\title{
Online Food Ordering System
}

\author{
Oshonik Kamble ${ }^{1}$ \\ Computer Department, Pune Vidyarthi Griha’s College of Engineering \& Technology, Pune, India ${ }^{1}$
}

\begin{abstract}
As Sweegy, Zomato, Food panda are limited with only restaurants and cafe where we can place orders. All the time it is not affordable and healthy for people to order the food from the restaurants, so there is need of an application which will provide the facility of home - made food and mess too. So from this application, we are filling the gap of availability of mess and chef which is not in other food delivery apps. First Highlighting feature of our application is chef-at-home. And second is Free Food in which user can earn through performing the tasks and same can be used for ordering the food from app only. This app will deal with the real time data as data of food posted on each day will be invalid after one day. Various messes can register through this app and can start their own business. The App will also provide the facility of booking the caterers for various events.
\end{abstract}

Keywords: Android app, Food ordering system

\section{INTRODUCTION}

The on-line food ordering system sets up food menu online and clients will simply place the order from restaurants and cafes as per they like however each customer might not breach time afford it. Client like students or unemployed individuals can't afford all the time and that they might have a home-brewed food. furthermore the food that is accessible from restaurants there's no accessibility of home grilled food. Since there's constant migration of individuals in varied states, edifice food isn't assumed to be healthy for normal consumption. the most motivation for it's increasing use of food delivery system on single click.

The convergence of wireless and mobile technologies will facilitate omnipresent platform for implementing business applications like food ordering system through mess. with none info and communication technology facilities, food ordering procedures at mess is presently not exist and users of mess got to visit a every and each mess close to him and compare the menu and rate then decide, therefore it'll save the time and efforts of user and suggest the messes in keeping with rating provided by visited users review.

\section{LITERATURE REVIEW}

In [1] an automated food ordering system is proposed which will keep track of user orders smartly. Basically, they implemented a food ordering system for different type of restaurants in which user will make order or make custom food by one click only. By means of android application for Tablet PCs this system was implemented. The front end was developed using JAVA, Android and at the backend MySQL database was used.

In [2] Customer using a Smartphone is considered as a basic assumption for the system. When the customer approach to the restaurant, the saved order can be confirmed by touching the Smartphone. The list of selected preordered items shall be shown on the kitchen screen, and when confirmed, order slip shall be printed for further order processing. The solution provides easy and convenient way to select pre-order transaction form.

In [3] there was an attempt to design and implementation of digital dining in restaurants using android technology. This system was a basic dynamic database utility system which fetches all information from a centralized database. This application improved the accuracy and efficiency of restaurants as well as human errors. Earlier drawbacks of automated food ordering systems were overcome by this system and it requires a onetime investment for gadgets. In [4] an application of integration of hotel management systems by web services technology is presented. Ordering System Kitchen Order Ticket (KOT), Billing System, Customer Relationship Management system (CRM) are held together by the Digital Hotel Management. Add or expand of hotel software system in any size of hotel chains environment was possible with this solution. In [5] research work aims to design and develop a wireless food ordering system in the restaurant. Technical operations of Wireless Ordering System (WOS) including systems architecture, function, limitations and recommendations were presented in this system. By providing higher quality customer service and reducing human errors to improve the management aspect for restaurants, pervasive application will be a valuable tool due to the high demands of handheld devices such as PDAs. 
Vol. 8, Issue 5, May 2019

\section{PROPOSED SYSTEM}

The food business may be a combination of the many various businesses and it's responsible for feeding the planet population. Our model consists of specific login choices for various users like emptor, seller, chef likewise as caterers. If the client login into the applying then the various menu contents ,book chef and book caterers choices are displayed. If chef/caterer login into application then he will be able to see the notification and conjointly he will update the knowledge regarding himself and might settle for or reject the client request. there is an alternative choice that's seller, seller are often single person or mess who will update his data concerning varied dishes and daily menus.

The model workflow starts with varied login choices like buyer, seller, cook and supplier. The authentication for explicit user has been taken place then once authentication data mining algorithms area unit applied thus totally different recommendation of the food is provided per specific area. once buyer logged into application then the activities performed by buyer are analyzed through particular data analytics rule.

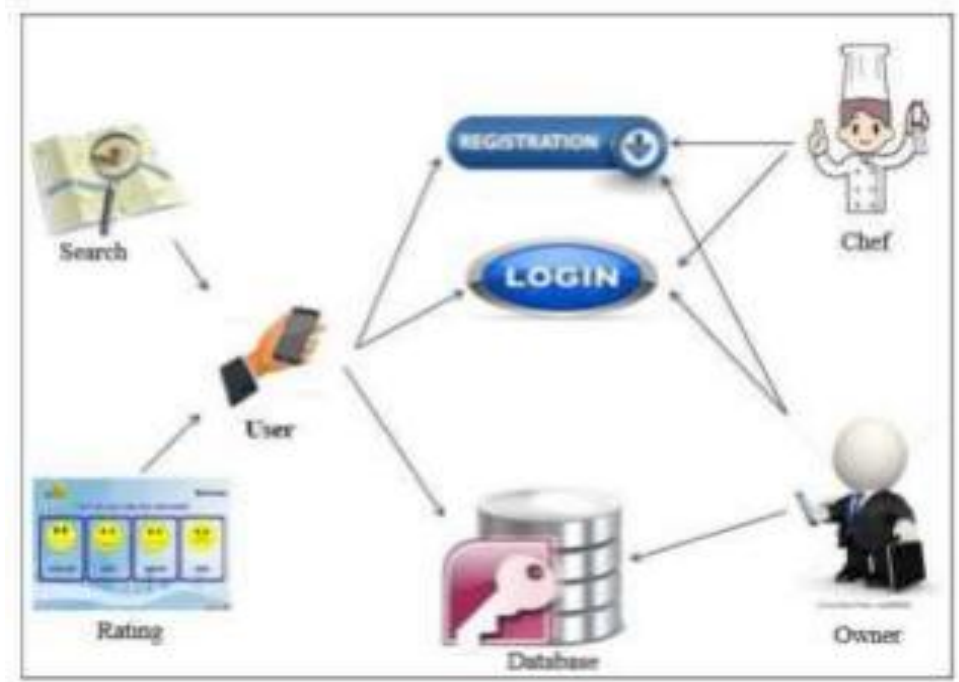

\section{ARCHITECTURAL DESIGN}

The main modules in this android application of homemade ordering system are:-

Buyers: When the buyer wants to book chef or caterers, the notification is generated for particular chef or caterers. Then chef or caterer can accept or reject the buyer's request. If the request of buyer is accepted ,buyers can choose the menu he want to buy and place order or book chef or book caters which he want and can make payement using paytm, money wallet etc.

Admin: Admin is responsible for registration purpose, after the authentication of admin user can access the system. Admin is also responsible for adding user, updating other modules, handling and management of all other modules in the application.

Sellers: When the seller wants to add dishes, "Add Menu" just needs to be Clicked, on that page, the detailed information of existing dishes will be shown, such as Product Name, Category Belong, Sell Price, the state of sale, etc and according to that seller can add new food item. Seller is also responsible of accepting or rejecting the request of buyer.After accept of buyers seller get details and location of buyers.

Chef : When the chef wants to add dishes, "Add Menu" just needs to be Clicked, on that page, the detailed information of existing dishes will be shown, such as Product Name, Category Belong, Sell Price, the state of sale, etc and according to that seller can add new food item. Chef is also responsible of accepting or rejecting the request of buyer. After accept of buyers chef get details and location of buyers.

Caterers: When the caterers wants to add dishes, "Add Menu" just needs to be Clicked, on that page, the detailed information of existing dishes will be shown, such as Product Name, Category Belong, Sell Price, the state of sale, etc and according to that seller can add new food item. Caterers is also responsible of accepting or rejecting the request of buyer. After accept of buyers caterers get details and location of buyers. 
Vol. 8, Issue 5, May 2019

\section{RESULTS}

The result of our system application includes an Android Application as well as a Web-based application. Once a customer places an order for a restaurant / mess, he/she will get the order Id on the screen dynamically. The customer can check the status of the order through the Order Status interface provided in the GUI of the application. We have developed the system application in such a way that the customer can order the food first and then enter the required credentials while checkout. Once the order is delivered to the customer, a feedback mail is send to the customer regarding his experience with the entire application. The feedback mail consists of the star rating still as comments of the client. The customer can track his order through the Tracking Interface provided in the GUI of the application. The restaurant / mess owner as well as customer can track the order in our system application. The preview of this tracking system is shown below:

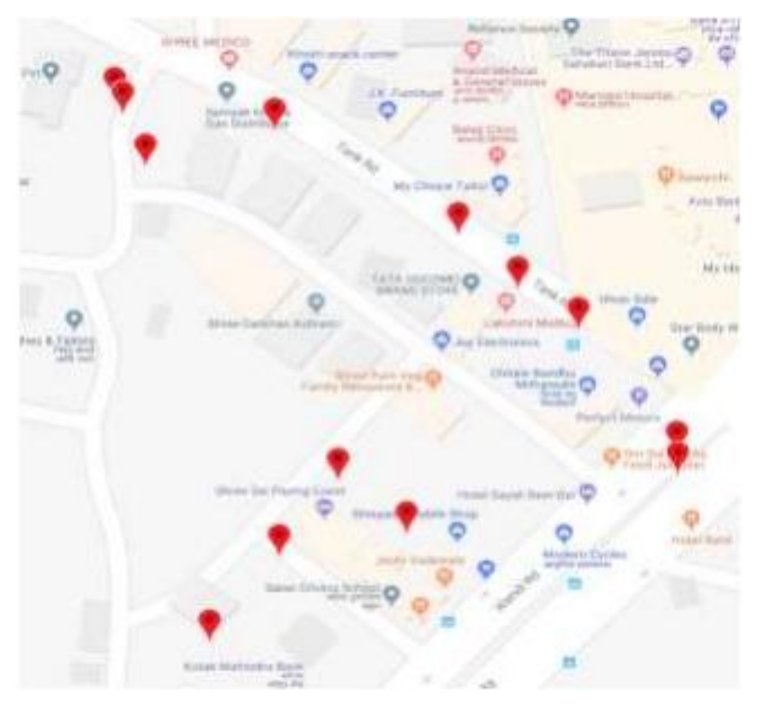

VI. CONCLUSION

It facilitates users to order food easily. It also gives option to pay. Having all the options on internet like menu, discount, online transactions, customers can easily access it. By providing homemade food, it will be convenient for those who have migrated to other cities. Eating fast food daily is not good for health as well and mostly hostelite's loves to eat homemade food rather than restaurant food, So it's best to give them such an amazing option to enjoy homemade food. Our Chef-at-home feature will give customers guaranty of fresh food. Large number of people can make a use of proposed system because now a days, people are migrating to other cities in search of jobs. It can be concluded that, based on the application: Orders are made easily by this system; Information needed in making order to customer is provided by the system. Receiving orders and modifying its data is possible through the application and it also helps admin in controlling all the Food system.

\section{REFERENCES}

[1]. Kirti Bhandge, Tejas Shinde, Dheeraj Ingale, Neeraj Solanki, Reshma Totare,"A Proposed System for Touchpad Based Food Ordering System Using Android Application", International Journal of Advanced Research in Computer Science Technology (IJARCST 2015).

[2]. Varsha Chavan, Priya Jadhav,Snehal Korade,Priyanka Teli, "Implementing Customizable Online Food Ordering System Using Web Based Application", International Journal of Innovative Science, Engineering Technology(IJISET) 2015.

[3]. Resham Shinde, Priyanka Thakare, Neha Dhomne, Sushmita Sarkar, ”Design and Implementation of Digital dining in Restaurants using Android", International Journal of Advance Research in Computer Science and Management Studies 2014.

[4]. Ashutosh Bhargave, Niranjan Jadhav, Apurva Joshi, Prachi Oke, S. R Lahane,"Digital Ordering System for Restaurant Using Android", International Journal of Scientific and Research Publications 2013.

[5]. Khairunnisa K., Ayob J., Mohd. Helmy A. Wahab, M. Erdi Ayob, M. Izwan Ayob, M. Afif Ayob, "The Application of Wireless Food Ordering System" MASAUM Journal of Computing 2009.

[6]. Noor Azah Samsudin, Shamsul Kamal Ahmad Khalid, Mohd Fikry Akmal Mohd Kohar, Zulkifli Senin, Mohd Nor Ihkasan,” A customizable wireless food ordering system with real time customer feedback", IEEE Symposium on Wireless Technology and Applications(ISWTA) 2011.

[7]. Serhat Murat Alagoza, Haluk Hekimoglub," A study on tam: analysis of customer attitudes in online food ordering system", Elsevier Ltd. 2012.

[8]. Patel Krishna, Patel Palak, Raj Nirali, Patel Lalit," Automated Food Ordering System", International Journal of Engineering Research and Development (IJERD) 2015.

[9]. Mayur D. Jakhete, Piyush C. Mankar," Implementation of Smart Restaurant with e-menu Card," International Journal of Computer Applications 2015 of Smart Restaurant with emenu Card, "International Journal of Computer Applications 2015 